\title{
A Novel Approach for Fault Classification and Fault Phase Selection for Transmission Lines
}

\author{
K. Ravi narayana ${ }^{1}$, Dr. V. Ganesh ${ }^{2}$ \\ PG scholar, Dept. of EEE, JNTUA college of Engineering, Pulivendula, Kadapa(dt) A.P, India ${ }^{1}$
}

Associate Professor, Dept. of EEE, JNTUA college of Engineering, Pulivendula, Kadapa(dt) A.P, India ${ }^{2}$

\begin{abstract}
Transmission lines are used to transmit electric power for large distances in electrical power systems. The rapid growth of electrical power systems over the past few decades has resulted in a massive increase of the quantity of lines operative and their total length. These lines are exposed to faults as a result of lightning, short circuits, faulty equipment's \&human errors. This paper presents a novel approach for fault classification and faulted phase selection for Transmission lines that is dispensed with sequential reactive power components. The proposed technique has been taking a look at about two cases and every case has eighteen test cases from each end. This technique identifies single line to ground fault, double line to ground fault $\&$ double line faults for given test case systems and this is implemented using Mat Lab software package.
\end{abstract}

Keywords: Transmission lines, lightning,s hort circuits, Sequential Reactive power components.

\section{INTRODUCTION}

Transmission lines are a vital a part of the electrical power system, as they give the path to transfer power between generation and load. The significant challenge to the transmission line protection lies in faithfully identifying and separating faults compromising the protection of the system. This paper presents fault classification and fault phase selection using sequential reactive power components. The Symmetrical components are measured on the each side, i.e. sending end and receiving end. The reactive power formed by positive and negative sequence components is employed to classify the faults and the lines involved.

BehnamMahamedi and JianGuo Zhu [1] proposed a fault classification and fault phase selection technique based on the symmetrical components of reactive power for single circuit transmission lines. It uses only two limits to judge the fault classification and faulted phase selection and the different fault cases are evaluated to reveal the capability of the proposed method.

Lin et al [2] put forward a faulted phase selection method based on super imposed positive and negative sequence currents combined with correlation theory, which was used to calculate the angle between two signals. It can be found out that the method is highly vulnerable to fault resistance.

Benmuoyal and Masheredjian [3] put forward an interesting method to determine the direction of faults and fault phase selection based on the ratio of differential super imposed voltage to differential superimposed current. It can be found out that thresholds required for the method is not an easy task.

Adu [4] presented an accurate fault classificationtechnique for power system monitoring devices based onthe phase angles between superimposed positive and negative sequence currents. The method also used the relative magnitudes of the zero and negative sequence currents with respect to the positive sequence current todifferentiate between the grounded and ungrounded faults. Move over the method failed for non- zero fault resistance.

Z. Q. BO et al [5] proposed a positional protection of transmission line using fault generated high frequency transient signals (by introducing the digital signal processing). These methods benefit from the specific transient patterns of electrical signal after fault inception. The success rate of these methods, however, highly depends on the sampling frequency [6].

K. M. Silva et al [7] presented an interesting method Haar Wavelet based method for fast fault classification in transmission lines was based on calculating the energy of detail coefficients of the phase currents. The performance of the method is jeopardized due to fault incident angle variations.

Xinzhou Dong et al [8] put forward a fault classification and faulted phase selection based on the initial current traveling wave. The characteristics of various faults were investigatedon the basis of the Karenbauer transform. The sampling frequency adopted for evaluation studies was chosen $400 \mathrm{KHZ}$ which is much more than common sampling frequency used numerical relays[9]. Typically, high sampling frequency is the main dis advantages of transient based method.

\section{Proposed Method}

The proposed method is based on the symmetrical components of reactive power. It is well-defined as follows 


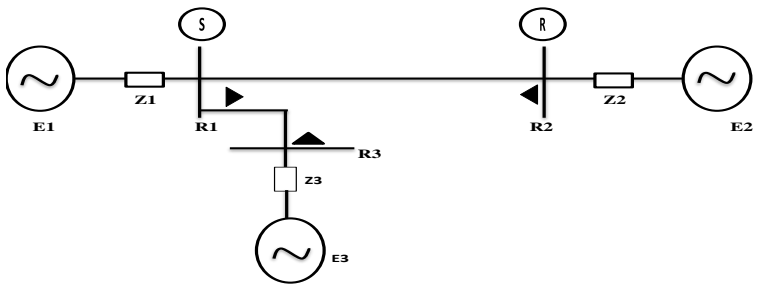

Fig. 1 Transmission line protected by the relays at the ends Here E1 is sending end and E2, E3 are receiving ends. By observing the figure one it can be derived as

$$
\begin{aligned}
& \mathrm{Q}_{1}=\operatorname{imag}\left\{\mathrm{V}_{1} \times \mathrm{I}_{1} *\right\} \\
& \mathrm{Q}_{2}=\operatorname{imag}\left\{\mathrm{V}_{2} \times \mathrm{I}_{2} *\right\} \\
& \mathrm{Q}_{0}=\operatorname{imag}\left\{\mathrm{V}_{0} \times \mathrm{I}_{0} *\right\}
\end{aligned}
$$

Where $\mathrm{Q}_{1}, \mathrm{Q}_{2}$ and $\mathrm{Q}_{0}$ are respectively positive sequence reactive power, negative sequence reactive power and zero sequence reactive power. Similarly $\mathrm{V}_{1}, \mathrm{~V}_{2}, \mathrm{~V}_{0}, \mathrm{I}_{1}, \mathrm{I}_{2}$ and $\mathrm{I}_{0}$ are respectively positive, negative, zero sequence components of voltage and current measured at relay points (either receiving or sending end). In this paper $\mathrm{Q}_{0}$, $\mathrm{Q}_{1}$ and $\mathrm{Q}_{2}$ are used to evaluate the proposed method.

\section{II.I Technique for single line to ground fault.}

Assume that the single line to ground fault at some ' $\mathrm{m}$ ' distance in the transmission line from relay point $R_{1}$ as shown in the Fig. 1. All sequence components of voltages and currents are measured from both the sending end and receiving end relays then calculate the zero and negative sequence reactive powers of both ends.

The ratio of the zero sequence reactive power to the negative sequence reactive power for both the ends are calculated then both or any one of the ends $\mathrm{Q}_{0} / \mathrm{Q}_{2}$ ratio is greater than 1 then it is a single line to ground fault.

$$
\frac{\mathrm{Q}_{0 \mathrm{~S}}}{\mathrm{Q}_{2 \mathrm{~S}}}>1
$$

In the equation four subscript $\mathrm{S}$ is represented to tell that it is obtained from the sending end measurements.

$$
\frac{\mathrm{Q}_{0 \mathrm{R}}}{\mathrm{Q}_{2 \mathrm{R}}}>1
$$

In the equation five subscript $\mathrm{R}$ is represented to tell that it is obtained from the receiving end measurements.

$$
\mathrm{Q}_{20}=\text { image }\left\{\left(\mathrm{V}_{2}+\mathrm{V}_{0}\right) \times\left(\mathrm{I}_{2}+\mathrm{I}_{0}\right) *\right\}
$$

From the above equations $4,5 \& 6$ it is clear that it is a After the fault is injected, first check the phase to phase single line to ground fault and another task is identifying the faulted line by checking on which phase $\mathrm{Q}_{20}$ is the maximum that is the faulted line.

\section{II.II Technique for double line to ground fault.}

Assume that the double line to ground fault at some ' $\mathrm{m}$ ' distance in the transmission linefrom relay point $R_{1}$ as shown in Fig. 1. All sequence components of voltages and currents are measured from both the sending end and receiving end relays then calculate the zero and negative sequence reactive powers of both ends.

The ratio of zero sequence reactive power to the negative sequence reactive power for both the ends are calculated then both of the ends $\mathrm{Q}_{0} / \mathrm{Q}_{2}$ ratio is in between 0 and 1 then it is a double phase to earth fault.

$$
\begin{gathered}
0<\frac{\mathrm{Q}_{0 \mathrm{~S}}}{\mathrm{Q}_{2 \mathrm{~S}}}<1 \\
0<\frac{\mathrm{Q}_{0 \mathrm{R}}}{\mathrm{Q}_{2 \mathrm{R}}}<1 \\
\mathrm{Q}_{20}=\operatorname{imag}\left\{\left(\mathrm{V}_{2}+\mathrm{V}_{0}\right) \times\left(\mathrm{I}_{2}+\mathrm{I}_{0}\right) *\right\}
\end{gathered}
$$

From the above equations $7,8 \& 9$ it is clear that it is a double phase to earth fault and another task is identifying the faulted phases by checking on which phases the $\mathrm{Q}_{20}$ is minimum those phases are affected phases.

\section{II.III Technique for line to line fault.}

Assume that the phase to phase fault at some ' $\mathrm{m}$ ' distance in the transmission line from relay point $\mathrm{R}_{1}$ of Fig. 1. All sequence components of voltages and currents are measured before the fault and after the fault. Calculate the $\mathrm{Q}_{12}$ as below

$$
\mathrm{Q}_{12}=\operatorname{imag}\left\{\left(\mathrm{V}_{1}+\mathrm{V}_{2}\right) \times\left(\mathrm{I}_{1}+\mathrm{I}_{2}\right) *\right\}
$$

$\mathrm{Q}_{12}$ is the reactive power measured by the relay on the each phase and after the fault there is no change in the current of healthy phase. If the $\Delta \mathrm{Q}_{12}$ is equal to zero, then it is healthy phase and $\Delta \mathrm{Q}_{12}$ is not equal to zero then it is faulted phase. Therefore, from this the phase to phase fault is determined by checking the $\Delta \mathrm{Q}_{12}$. Another task is identifying the faulted phases, it is simply done by the same procedure as $\Delta \mathrm{Q}_{12}$ is zero on the phase it is healthy phase and another two phases are not healthy phases.

\section{II.IV Algorithm for Proposed method}

Step 1:

Sample the parameters of three phase voltage and current from the relay points.

Step 2:

Calculate the symmetrical components of the voltage and current.

Step 3:

Sequential reactive powers $\mathrm{Q}_{0}, \mathrm{Q}_{1} \& \mathrm{Q}_{2}$ are calculated from the symmetrical components.

Step 4:

fault by $\Delta \mathrm{Q}_{12}$ is not zero on the any one of the phase then it is a line to line fault and find out the faulted phases.

Step 5:

If it is equal to zero on all lines, then it's not a line to line fault, then, check for the double line to ground fault by the ratio $\mathrm{Q}_{0} / \mathrm{Q}_{2}$ is in between zero and one for both relays then, it'll be declared as a double line to ground fault and find out the faulted lines with the ground.

Step 6:

If the ratio is larger than one it'll be declared as single line to ground fault and find out the faulted phase with the ground. These steps are for both cases $1 \& 2$ and also for its test cases. 
INTERNATIONAL JOURNAL OF INNOVATIVE RESEARCH IN ELECTRICAL, ELECTRONICS, INSTRUMENTATION AND CONTROL ENGINEERING Vol. 2, Issue 12, December 2014

\section{RESULTS}

III.I Case -I, when a fault occurs between $E_{1} \& E_{2}$

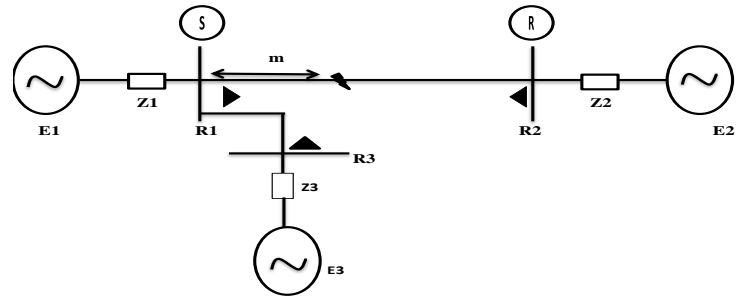

FIG. 3 SIMULATED SYSTEM CASE 1

The simulated system details in fig. 3 are $\mathrm{E}_{1}=400 \mathrm{KV}$, $50 \mathrm{~Hz}$ and $\mathrm{E}_{2}=380 \mathrm{KV}, 50 \mathrm{~Hz}$ and transmission line length is 200 Kilo meters.

Source impedances:

$$
\begin{gathered}
\mathrm{Z}_{11}=\mathrm{Z}_{2 \mathrm{~S}}=0.32+\mathrm{j} 6.56 \Omega \\
\mathrm{Z}_{01}=1.76+\mathrm{j} 9.28 \Omega \\
\mathrm{Z}_{13}=\mathrm{Z}_{2 \mathrm{R}}=0.48+\mathrm{j} 8.8 \Omega \\
\mathrm{Z}_{03}=1.76+\mathrm{j} 11.68 \Omega
\end{gathered}
$$

Transmission line parameters :( distributed model)

\begin{tabular}{|c|c|c|c|}
\hline Cases & $\begin{array}{c}\text { Fault } \\
\text { type }\end{array}$ & $\begin{array}{c}\text { Fault distance } \\
\text { (Kilo meters) }\end{array}$ & $\begin{array}{c}\text { Fault } \\
\text { resistance } \\
(\Omega)\end{array}$ \\
\hline 1 & AG & 100 & 10 \\
\hline 2 & AG & 190 & 10 \\
\hline 3 & BG & 100 & 50 \\
\hline 4 & BG & 190 & 50 \\
\hline 5 & CG & 100 & 100 \\
\hline 6 & CG & 190 & 100 \\
\hline 7 & $\mathrm{ABG}$ & 100 & 10 \\
\hline 8 & $\mathrm{ABG}$ & 190 & 10 \\
\hline 9 & BCG & 100 & 50 \\
\hline 10 & BCG & 190 & 50 \\
\hline 11 & $\mathrm{CAG}$ & 100 & 100 \\
\hline 12 & CAG & 190 & 100 \\
\hline 13 & $\mathrm{AB}$ & 100 & 10 \\
\hline 14 & $\mathrm{AB}$ & 190 & 10 \\
\hline 15 & $\mathrm{BC}$ & 100 & 50 \\
\hline 16 & $\mathrm{BC}$ & 190 & 50 \\
\hline 17 & $\mathrm{CA}$ & 100 & 100 \\
\hline 18 & $\mathrm{CA}$ & 190 & 100 \\
\hline
\end{tabular}

$$
\begin{gathered}
\mathrm{Z}_{1 \mathrm{~L}}=\mathrm{Z}_{2 \mathrm{~L}}=0.021+\mathrm{j} .278 \Omega / \mathrm{km} \\
\mathrm{Z}_{0 \mathrm{~L}}=0.302+\mathrm{j} 0.905 \Omega / \mathrm{km} \\
\mathrm{C}_{1 \mathrm{~L}}=13.170 \mathrm{nF} / \mathrm{km} \\
\mathrm{C}_{0 \mathrm{~L}}=8.396 \mathrm{nF} / \mathrm{km}
\end{gathered}
$$

\begin{tabular}{|c|c|c|c|c|}
\hline \multirow{2}{*}{ Case } & \multirow{2}{*}{$\mathbf{Q}_{0} / \mathbf{Q}_{2}$} & \multicolumn{3}{|c|}{$\left|\mathbf{Q}_{20}\right|$} \\
\hline & & $\left|\mathbf{Q}_{20}\right|_{A}$ & $\left|\mathbf{Q}_{20}\right|_{\mathbf{B}}$ & $\left|\mathbf{Q}_{20}\right|_{\mathrm{C}}$ \\
\hline 1 & 0.9970 & $4.3720 * 10^{7}$ & $1.0566 * 10^{7}$ & $1.1221 * 10^{7}$ \\
\hline 2 & 0.3067 & $3.4283^{*} 10^{7}$ & $1.2161 * 10^{7}$ & $0.9299 * 10^{7}$ \\
\hline 3 & 0.9950 & $0.3704 * 10^{7}$ & $1.4258 * 10^{7}$ & $0.3401 * 10^{7}$ \\
\hline 4 & 0.3059 & $1.8668 * 10^{6}$ & $6.8480 * 10^{6}$ & $2.4218 * 10^{6}$ \\
\hline 5 & 0.9957 & $0.9416^{*} 10^{6}$ & $1.0180 * 10^{6}$ & $3.9325 * 10^{6}$ \\
\hline 6 & 0.3059 & $0.6728 * 10^{6}$ & $0.5165 * 10^{6}$ & $1.8986 * 10^{6}$ \\
\hline 7 & 0.0855 & $4.8767 * 10^{7}$ & $3.0582 * 10^{7}$ & $7.9582 * 10^{7}$ \\
\hline 8 & 0.0583 & $4.7002 * 10^{7}$ & $2.3729 * 10^{7}$ & $5.6266 * 10^{7}$ \\
\hline 9 & 0.0264 & $5.4312 * 10^{7}$ & $4.5842 * 10^{7}$ & $3.0651 * 10^{7}$ \\
\hline 10 & 0.0081 & $3.2757 * 10^{7}$ & $3.1059 * 10^{7}$ & $2.4152 * 10^{7}$ \\
\hline 11 & 0.0190 & $1.0779 * 10^{7}$ & $1.7165 * 10^{7}$ & $1.3223 * 10^{7}$ \\
\hline 12 & 0.0046 & $1.2389 * 10^{7}$ & $1.5703 * 10^{7}$ & $1.4202 * 10^{7}$ \\
\hline
\end{tabular}

Table. 1 Different fault cases for evaluation of simulated system cases $1 \& 2$ are shown.
Table. 2 Sequential reactive power components and ratio of zero sequence reactive power to the negative sequence reactive power from the sending end relay point is shown.

Table. 3 Sequential reactive power components and ratio of zero sequence reactive power to the negative sequence reactive power from the receiving end relay point are shown.

\begin{tabular}{|c|c|c|c|c|}
\hline \multirow{2}{*}{ Case } & \multirow{2}{*}{$\mathbf{Q}_{\mathbf{0}} / \mathbf{Q}_{2}$} & \multicolumn{3}{|c|}{$\left|\mathbf{Q}_{20}\right|$} \\
\cline { 3 - 5 } & & $\left|\mathbf{Q}_{20}\right|_{\mathbf{A}}$ & $\left|\mathbf{Q}_{20}\right|_{\mathbf{B}}$ & $\left|\mathbf{Q}_{20}\right|_{\mathbf{C}}$ \\
\hline 1 & 1.1825 & $3.8984 * 10^{10}$ & $0.9601 * 10^{10}$ & $0.996 * 10^{10}$ \\
\hline 2 & 1.4864 & $1.3182 * 10^{12}$ & $0.3243 * 10^{12}$ & $0.3545 * 10^{12}$ \\
\hline 3 & 1.1835 & $0.5130 * 10^{10}$ & $2.0006^{*} 10^{10}$ & $0.4928^{*} 10^{10}$ \\
\hline 4 & 1.4873 & $0.6640 * 10^{11}$ & $2.4711 * 10^{11}$ & $0.6084 * 10^{11}$ \\
\hline 5 & 1.1818 & $1.2485 * 10^{9}$ & $1.3014 * 10^{9}$ & $5.0727 * 10^{9}$ \\
\hline 6 & 1.4863 & $1.5334 * 10^{10}$ & $1.6765 * 10^{10}$ & $6.2341 * 10^{10}$ \\
\hline 7 & 0.1016 & $0.6147 * 10^{11}$ & $0.3619 * 10^{11}$ & $1.0244 * 10^{11}$ \\
\hline 8 & 0.2814 & $1.5114 * 10^{12}$ & $0.3325 * 10^{12}$ & $2.3013 * 10^{12}$ \\
\hline 9 & 0.0314 & $5.8584 * 10^{10}$ & $4.9015 * 10^{10}$ & $3.1406 * 10^{10}$ \\
\hline 10 & 0.0398 & $8.0558 * 10^{11}$ & $6.7396 * 10^{11}$ & $3.9809 * 10^{11}$ \\
\hline 11 & 0.0225 & $1.168 * 10^{10}$ & $1.9363 * 10^{10}$ & $1.4686^{11} 10^{10}$ \\
\hline 12 & 0.0226 & $2.3739 * 10^{11}$ & $3.9704 * 10^{11}$ & $3.0664 * 10^{11}$ \\
\hline & & & & \\
\hline & & & & \\
\hline
\end{tabular}


From the tables $2 \& 3$ it is clear that the ratio of $\mathrm{Q}_{0} / \mathrm{Q}_{2}$ is greater than one on any one of the relay points, then it is line to ground fault and the maximum $\mathrm{Q}_{20}$ is represents the faulted line. The ratio of $\mathrm{Q}_{0} / \mathrm{Q}_{2}$ is less than one on both ends of relay point, then it is line to line ground fault and the minimum $\mathrm{Q}_{20}$ on the line represents the faulted lines.

Therefore, as tabulated in the tables $2 \& 3$ this confirmed a line to ground faults and double line to ground faults in simulated system case 1 .

Table. $4 \Delta \mathrm{Q}_{12}$ Sequential reactive power components in line $\mathrm{A}$, line $\mathrm{B}$ and line $\mathrm{C}$ from the sending end relay point are shown.

\begin{tabular}{|c|c|c|c|}
\hline \multirow{2}{*}{ Case } & \multicolumn{3}{|c|}{$\Delta \mathbf{Q}_{\mathbf{1 2}}$} \\
\cline { 2 - 4 } & $\Delta \mathbf{Q}_{\mathbf{1 2 \mathbf { A }}}$ & $\Delta \mathbf{Q}_{\mathbf{1 2}}$ & $\Delta \mathbf{Q}_{\mathbf{1 2}} \mathbf{C}$ \\
\hline 13 & $-2.4425 * 10^{8}$ & $-6.6953 * 10^{8}$ & 0 \\
\hline 14 & $-2.5875 * 10^{8}$ & $-6.6953 * 10^{8}$ & 0 \\
\hline 15 & 0 & $-6.6658^{*} 10^{7}$ & $-3.1365^{*} 10^{8}$ \\
\hline 16 & 0 & $-5.2376^{*} 10^{7}$ & $-2.5146^{*} 10^{8}$ \\
\hline 17 & $-1.4195 * 10^{8}$ & 0 & $-7.6177^{*} 10^{7}$ \\
\hline 18 & $-1.1252^{*} 10^{8}$ & 0 & $-5.9031^{*} 10^{7}$ \\
\hline
\end{tabular}

Table. $5 \Delta Q_{12}$ Sequential reactive power components in line $\mathrm{A}$, line $\mathrm{B}$ and line $\mathrm{C}$ from the receiving end relay point are shown.

\begin{tabular}{|c|c|c|c|}
\hline \multirow{2}{*}{ Case } & \multicolumn{3}{|c|}{$\Delta \mathbf{Q}_{\mathbf{1 2}}$} \\
\cline { 2 - 4 } & $\Delta \mathbf{Q}_{\mathbf{1 2 \mathbf { A }}}$ & $\Delta \mathbf{Q}_{\mathbf{1 2}} \mathbf{B}$ & $\Delta \mathbf{Q}_{\mathbf{1 2}} \mathbf{C}$ \\
\hline 13 & $-7.2105 * 10^{9}$ & $-3.1582^{*} 10^{11}$ & 0 \\
\hline 14 & $-6.1905 * 10^{11}$ & $-1.6690 * 10^{12}$ & 0 \\
\hline 15 & 0 & $-4.0706 * 10^{10}$ & $-1.0574 * 10^{11}$ \\
\hline 16 & 0 & $-7.5076^{11}$ & $-7.7460^{11} * 10^{11}$ \\
\hline 17 & $2.4189 * 10^{10}$ & 0 & $-2.9516^{11} 10^{10}$ \\
\hline 18 & $-2.3925 * 10^{11}$ & 0 & $-4.7790^{*} 10^{11}$ \\
\hline
\end{tabular}

As tabulated in the tables $4 \& 5, \Delta Q_{12}$ is zero on the healthy lines while they were not zero on the faulted lines this confirmed a line to line faults for case 1 .

From the tables $2,3,4 \& 5$ it is clear that the single line to ground, double line to ground and double line faults are effectively identified by the proposed method in the case 1 and also lines which are affected.

\section{III.II Case - II, when a fault occurs between $\mathbf{E}_{2} \& \mathbf{E}_{3}$}

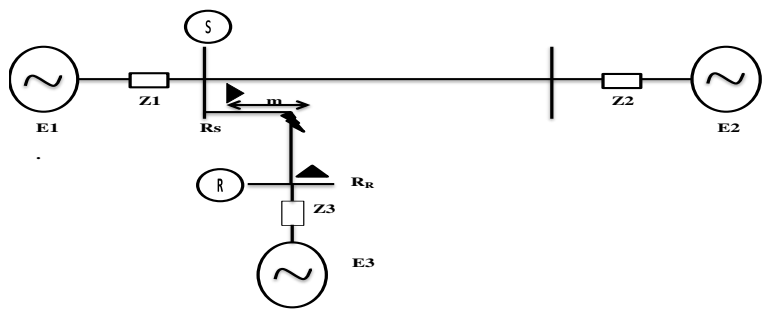

Fig.4 Simulated System Case 2

The simulated system details in fig. 3 are $E_{1}=400 \mathrm{KV}$, $50 \mathrm{~Hz}$ and $\mathrm{E}_{3}=380 \mathrm{KV}, 50 \mathrm{~Hz}$ and transmission line length is 200 Kilo meters.

Source impedances:

$$
\begin{gathered}
\mathrm{Z}_{11}=\mathrm{Z}_{2 \mathrm{~S}}=0.32+\mathrm{j} 6.56 \Omega \\
\mathrm{Z}_{01}=1.76+\mathrm{j} 9.28 \Omega \\
\mathrm{Z}_{13}=\mathrm{Z}_{2 \mathrm{R}}=0.48+\mathrm{j} 8.8 \Omega \\
\mathrm{Z}_{03}=1.76+\mathrm{j} 11.68 \Omega
\end{gathered}
$$

Transmission line parameters :( distributed model)

$$
\begin{gathered}
\mathrm{Z}_{1 \mathrm{~L}}=\mathrm{Z}_{2 \mathrm{~L}}=0.021+\mathrm{j} .278 \Omega / \mathrm{km} \\
\mathrm{Z}_{0 \mathrm{~L}}=0.302+\mathrm{j} 0.905 \Omega / \mathrm{km} \\
\mathrm{C}_{1 \mathrm{~L}}=13.170 \mathrm{nF} / \mathrm{km} \\
\mathrm{C}_{0 \mathrm{~L}}=8.396 \mathrm{nF} / \mathrm{km}
\end{gathered}
$$

\begin{tabular}{|c|c|c|c|c|}
\hline \multirow{2}{*}{ Case } & \multirow{2}{*}{$\mathbf{Q}_{0} / \mathbf{Q}_{2}$} & \multicolumn{3}{|c|}{$\left|\mathbf{Q}_{20}\right|$} \\
\hline & & $\left|Q_{20}\right|_{A}$ & $\left|Q_{20}\right|_{B}$ & $\left|Q_{20}\right|_{C}$ \\
\hline 1 & 0.9980 & $6.5353 * 10^{7}$ & $1.5810^{*} 10^{7}$ & $1.6756^{*} 10^{7}$ \\
\hline 2 & 0.3065 & $3.0682 * 10^{7}$ & $1.0891 * 10^{7}$ & $0.8321 * 10^{7}$ \\
\hline 3 & 0.9958 & $0.5245^{*} 10^{7}$ & $2.0310^{*} 10^{7}$ & $0.4875^{*} 10^{7}$ \\
\hline 4 & 0.3060 & $1.6970^{*} 10^{6}$ & $6.2340 * 10^{6}$ & $2.2073 * 10^{6}$ \\
\hline 5 & 0.9970 & $1.5704 * 10^{6}$ & $1.6736^{*} * 10^{6}$ & $6.5102 * 10^{6}$ \\
\hline 6 & 0.3065 & $0.6332 * 10^{6}$ & $0.4844 * 10^{6}$ & $1.7851 * 10^{6}$ \\
\hline 7 & 0.1004 & $0.7941 * 10^{8}$ & $0.4281 * 10^{8}$ & $1.250 * 10^{8}$ \\
\hline 8 & 0.0581 & $4.2094 * 10^{7}$ & $2.1324 * 10^{7}$ & $5.0483 * 10^{7}$ \\
\hline 9 & 0.0265 & $8.2514^{*} 10^{7}$ & $6.9270 * 10^{7}$ & $4.6534 * 10^{7}$ \\
\hline 10 & 0.0081 & $2.9024 * 10^{7}$ & $2.7510^{*} * 10^{7}$ & $2.1406^{*} 10^{7}$ \\
\hline 11 & 0.0167 & $2.0498 * 10^{7}$ & $3.1842 * 10^{7}$ & $2.5220^{*} 10^{7}$ \\
\hline 12 & 0.0046 & $1.1235^{*} 10^{7}$ & $1.4236 * 10^{7}$ & $1.2873 * 10^{7}$ \\
\hline
\end{tabular}

Table. 6 Sequential reactive power components and ratio of zero sequence reactive power to the negative sequence reactive power from the sending end relay point are shown. 
Table. 7 Sequential reactive power components and ratio of zero sequence reactive power to the negative sequence reactive power from the receiving end relay point are shown.

\begin{tabular}{|c|c|c|c|c|}
\hline \multirow{2}{*}{ Case } & \multirow{2}{*}{$\mathbf{Q}_{0} / \mathbf{Q}_{2}$} & \multicolumn{3}{|c|}{$\left|\mathbf{Q}_{20}\right|$} \\
\hline & & $\left|\mathbf{Q}_{20}\right|_{A}$ & $\left|\mathbf{Q}_{20}\right|_{\mathbf{B}}$ & $\left|\mathbf{Q}_{20}\right|_{\mathrm{C}}$ \\
\hline 1 & 1.1835 & $9.9691 * 10^{10}$ & $2.4533 * 10^{10}$ & $2.5583 * 10^{10}$ \\
\hline 2 & 1.4867 & $1.3002 * 10^{12}$ & $0.3198 * 10^{12}$ & $0.3497 * 10^{12}$ \\
\hline 3 & 1.1847 & $1.0806 * 10^{10}$ & $4.2076^{*} 10^{10}$ & $1.0348 * 10^{10}$ \\
\hline 4 & 1.4868 & $0.6811 * 10^{11}$ & $2.5347 * 10^{11}$ & $0.6240 * 10^{11}$ \\
\hline 5 & 1.1838 & $0.3143^{*} 10^{10}$ & $0.3283 * 10^{10}$ & $1.2782 * 10^{10}$ \\
\hline 6 & 1.4864 & $1.7998^{*} 10^{10}$ & $1.9676 * 10^{10}$ & $7.3168 * 10^{10}$ \\
\hline 7 & 0.1193 & $1.8334 * 10^{I I}$ & $0.9192 * 10^{11}$ & $2.9473 * 10^{11}$ \\
\hline 8 & 0.2797 & $1.3366^{*} 10^{12}$ & $0.3062 * 10^{12}$ & $2.0694 * 10^{12}$ \\
\hline 9 & 0.0314 & $1.5864 * 10^{11}$ & $1.3190 * 10^{11}$ & $0.8504 * 10^{11}$ \\
\hline 10 & 0.0396 & $7.7137 * 10^{11}$ & $6.4754 * 10^{11}$ & $3.8187 * 10^{11}$ \\
\hline 11 & 0.0198 & $3.5999 * 10^{10}$ & $5.8109 * 10^{10}$ & $4.5331 * 10^{10}$ \\
\hline 12 & 0.0226 & $2.2634 * 10^{11}$ & $3.7828 * 10^{11}$ & $2.9235 * 10^{11}$ \\
\hline
\end{tabular}

From the tables $6 \& 7$ it is clear that the ratio of $\mathrm{Q}_{0} / \mathrm{Q}_{2}$ is greater than one on any one of the relay points, then it is line to ground fault and the maximum $\mathrm{Q}_{20}$ is represents the faulted line. The ratio of $\mathrm{Q}_{0} / \mathrm{Q}_{2}$ is less than one on both ends of relay point, then it is line to line ground fault and the minimum $\mathrm{Q}_{20}$ on the line represents the faulted lines. Therefore, as tabulated in the tables $6 \& 7$ this confirmed a line to ground faults and double line to ground faults in simulated system case 2 .

Table. $8 \Delta Q_{12}$ Sequential reactive power components in phase $\mathrm{A}$, phase $\mathrm{B}$ and phase $\mathrm{C}$ from the sending end relay point are shown.

\begin{tabular}{|c|c|c|c|}
\hline \multirow{2}{*}{ Case } & \multicolumn{3}{|c|}{$\Delta \mathbf{Q}_{\mathbf{1 2}}$} \\
\cline { 2 - 4 } & $\Delta \mathbf{Q}_{\mathbf{1 2 A}}$ & $\Delta \mathbf{Q}_{\mathbf{1 2}} \mathbf{B}$ & $\Delta \mathbf{Q}_{\mathbf{1 2}} \mathbf{C}$ \\
\hline 13 & $-2.8838 * 10^{8}$ & $-7.8930 * 10^{8}$ & 0 \\
\hline 14 & $-2.3027 * 10^{8}$ & $-5.8193 * 10^{8}$ & 0 \\
\hline 15 & 0 & -8.7703 & $-3.6782 * 10^{8}$ \\
\hline 16 & 0 & -4.8756 & $-2.2907 * 10^{8}$ \\
\hline 17 & $-1.6350 * 10^{8}$ & 0 & $-8.9753^{*} 10^{7}$ \\
\hline 18 & $-1.0388 * 10^{8}$ & 0 & $-5.4138^{*} 10^{7}$ \\
\hline
\end{tabular}

Table. $9 \Delta \mathrm{Q}_{12}$ Sequential reactive power components in phase $\mathrm{A}$, phase $\mathrm{B}$ and phase $\mathrm{C}$ from the receiving end relay point are shown.

\begin{tabular}{|c|c|c|c|}
\hline \multirow{2}{*}{ Case } & \multicolumn{3}{|c|}{$\Delta \mathbf{Q}_{\mathbf{1 2}}$} \\
\cline { 2 - 4 } & $\Delta \mathbf{Q}_{\mathbf{1 2 A}}$ & $\Delta \mathbf{Q}_{\mathbf{1 2}} \mathbf{B}$ & $\Delta \mathbf{Q}_{\mathbf{1 2}} \mathbf{C}$ \\
\hline 13 & $-5.9917 * 10^{10}$ & $-7.0667 * 10^{11}$ & 0 \\
\hline 14 & $-7.4061 * 10^{11}$ & $-2.0210^{11} 10^{12}$ & 0 \\
\hline 15 & 0 & $-1.3420^{*} 10^{11}$ & $-2.5761 * 10^{11}$ \\
\hline 16 & 0 & $-1.0937 * 10^{12}$ & $-1.1049^{11} 10^{12}$ \\
\hline 17 & $7.3128 * 10^{9}$ & 0 & $-8.9869^{*} * 10^{10}$ \\
\hline 18 & $-3.8151^{11} 10^{11}$ & 0 & $-7.5817^{*} 10^{11}$ \\
\hline
\end{tabular}

As tabulated in the tables $8 \& 9, \Delta Q_{12}$ is zero on the healthy lines while they were not zero on the faulted lines this confirmed a line to line faults for simulated system case 2 and from the tables $6,7,8 \& 9$ it is clear that the single line to ground, double line to ground and double line faults are effectively identified by the proposed method in the case 2 and also lines which are affected. Sequential reactive power components in all the tables are in VAR.

\section{IV.CONCLUSIONS}

This paper gives a novel approach for fault classification and fault phase selection for transmission lines with the positive, negative and zero sequential reactive power components. This method is easily implementedfor new transmission lines with protection technology using pilot scheme. The main advantage of this method is it works with constant thresholds, i.e. 1 and 0.The another advantage of proposed method can identify high resistance faults where existing methods fails such as current based methods. This method identifies faults such LG, LLG and LL for two test cases.

\section{REFERENCES}

[1] BehnamMahamedi and JianoGuo Zhu, senior member, IEEE. "Fault classification and faulted phase selection based on the symmetrical components of Reactivepower forsingle-circuit transmission lines," IEEE transactions on power delivery, vol. 28, no. 4, October 2013

[2] X. N. Lin, M. Zhao, K. Alymann, and P. Liu, "Novel design of a fast phase selector using correlation analysis," IEEE Trans. Power Del., vol. 20, no. 2, pt. 2, pp. 1283-1290, Apr. 2005.

[3] G.Benmouyal and J. Mahseredjian, "A combined directional and faulted phase selector element based on incremental quantities,"IEEE Trans. Power Del., vol. 16, no. 4, pp. 478-484, Oct. 2001

[4] T. Adu, "An accurate fault classification technique for power system monitoring devices," IEEE Trans. Power Del., vol. 17, no. 3, pp. 684-690, Jul. 2002.

[5] Z. Q. Bo, M. A. Redfern, and G. C. Weller, "Positional protection of transmission line using fault generated high frequency transient signals,"IEEE Trans. Power Del., vol.15,no.3,pp. 888-894,Jul.2000.

[6] W. L. A. Neves, N. S. D. Brito, B. A. Souza, and A. V. Fontes, "Sampling rate of digital fault recorders influence on fault diagnosis," in Proc. Transm. Distrib. Conf. Exp., Latin America, Nov. 2004, pp. 406-411.

[7] K.M.Silva,K. M.C. Dantas, B.A. Souza, N.S.D. Brito, F.B. Costa, and J.A.C.B.Silva, "Haar wavelet based method for fast fault 
ITERNATIONAL JOURNAL OF

Vol. 2, Issue 12, December 2014

classification in transmission lines," in Proc. IEEE/Power Eng. Soc.

Transm. Distrib. Conf. Exp., Latin America, Aug. 2006, pp. 1-5

[8] X.Dong, W.Kong, and T.Cui, "Fault classification and faulted-

phase selection based on the initial current traveling wave," IEEE

Trans. Power Del., vol. 24, no. 2, pp. 552-559, Apr. 2009.

[9] I.Zamora, A.J.Mazón, V. Valverde, E.Torres, and A.Dysko, "Power quality and digital protection relays,"presented at the Int. Conf. Renew. Energies Power Qual., Barcelona, Spain, 2004.

[10] H. Saadat, Power SystemAnalysis, $2^{\text {nd }}$ ed.NewYork: McGraw-Hill, 2002. 